\title{
TIGHT LABOR MARKETS AND THE DEMAND FOR EDUCATION: EVIDENCE FROM THE COAL BOOM AND BUST
}

\author{
DAN A. BLACK, TERRA G. MCKINNISH, and SETH G. SANDERS*
}

\begin{abstract}
Human capital theory predicts that individuals acquire less schooling when the returns to schooling are small. To test this theory, the authors study the effect of the Appalachian coal boom on high school enrollments. During the 1970 s, a boom in the coal industry increased the earnings of high school dropouts relative to those of graduates. During the $1980 \mathrm{~s}$, the boom subsided and the earnings of dropouts declined relative to those of graduates. The authors find that high school enrollment rates in Kentucky and Pennsylvania declined considerably in the 1970 s and increased in the 1980 s in coal-producing counties relative to counties without coal. The estimates indicate that a longterm $10 \%$ increase in the earnings of low-skilled workers could decrease high school enrollment rates by as much as $5-7 \%$-a finding with implications for policies aimed at improving low-skilled workers' employment and earnings, such as wage subsidies and minimum wage increases.
\end{abstract}

A simple model of human capital predicts that increases in wages of workers with low education relative to wages of workers with high education will reduce investments in schooling because the returns to additional years of schooling are

Dan A. Black is Trustee Professor of Economics, Center for Policy Research, Syracuse University; Terra G. McKinnish is Assistant Professor, Department of Economics, University of Colorado; and Seth G. Sanders is Professor of Economics, University of Maryland. The authors thank Steve Allen, Susan Black, Leigh Ann Leshock, Philip McGivney, Sameer Makada, Hoda Makar, Victoria Moyer, Reginald Roberts, and George Tita for their research assistance. Seth Sanders received support in the form of a Research Initiation Grant from Carnegie Mellon University. Black acknowledges research support from the Heinz School of Public Policy and Management at Carnegie Mellon University. The authors also gratefully acknowledge financial support from the National Science Foundation. diminished. In this paper, we exploit a rare opportunity to study the effect of a decrease in the wage gap between high school dropouts and high school graduates on high school enrollment by studying the coal boom and bust of the 1970s and 1980s. During the 1970s, the OPEC oil embargo drove up the price of coal and generated an enormous boom in the coal industry, substantially increasing demand for coal miners in rural Appalachia. Because coal miners were largely low-skilled workers, this increased the earnings of high school dropouts relative to those of high school graduates. During the 1980 s, the boom reversed into a bust, decreasing the earnings of dropouts relative to those of graduates. We

The data and computer programs used to generate the results here are available from the second author at the Department of Economics, UCB 256, University of Colorado, Boulder, CO 80309-0256. 
study the effect of the coal boom and bust on high school enrollment in Kentucky and Pennsylvania. These states contain coal-producing regions of Appalachia that were particularly affected by the boom and bust. By comparing high school enrollment changes in coal-mining counties to those in counties without coal mining during this time period, we can estimate the effect of the coal shocks on human capital investment.

An important feature of the coal boom is that it lasted for many years, generating a relatively long-term change in the wage differential between high school dropouts and high school graduates. The effect of a change in demand for low-skilled workers on high school enrollment or completion should depend on how long that change is expected to last. Students presumably consider how their projected post-graduation income stream compares with the income stream they can expect if they drop out and enter the labor force. A transitory change in wages for low-skilled workers will obviously affect the income stream of dropouts much less than will a long-term change. The distinction between the effects of transitory and long-term changes in the earnings of low-skilled workers is an important one in the context of current policy debates. There have been numerous proposals to increase the earnings of low-skilled workers through the creation of a publicsector jobs program, wage subsidies for low-skilled workers, or changes in the minimum wage. The enactment of these policies could generate very long-term changes in the earnings of low-skilled workers. It is therefore important to appreciate what sort of impact such policies might have on the educational attainment of students from low-income populations.

\section{Economic Conditions and Human Capital Investment}

This section considers the classical model of human capital investment as described in Mincer (1958) and Becker (1964). The decision to drop out of high school will depend on the wages of high school gradu- ates, $w_{g t}$ (where $w_{g t}$ is the earnings of a high school graduate at time $t$ ), and dropouts, $w_{d t}$. If person $j$ drops out of high school, the discounted value of the flow of earnings is

$$
E_{j d}=\sum_{t=0}^{T} \frac{w_{d t}}{\left(1+\rho_{j}\right)^{t}},
$$

where $\rho_{j}$ is the discount rate of person $j$. If instead person $j$ remains in school $k$ more years to complete high school, the present value of the flow of earnings of person $j$ is

$$
E_{j g}=\sum_{t=k}^{T} \frac{w_{g t}}{\left(1+\rho_{j}\right)^{t}} .
$$

Because public education is free, the student will complete school if $E_{j g}>E_{j d}$ :

$$
\begin{aligned}
& \sum_{t=k}^{T} \frac{\left(w_{g t}-w_{d t}\right)}{\left(1+p_{j}\right)^{t}}- \\
& \sum_{t=0}^{k-1} \frac{w_{d t}}{\left(1+\rho_{j}\right)^{t}}>0 .
\end{aligned}
$$

The first term in equation (3) reflects the return to a high school degree, the positive wage differential between high school graduates and high school dropouts. The second term reflects the opportunity cost of a high school education. If the student remains in high school and graduates, he or she forgoes those $k$ years of earnings. If the higher earnings associated with a high school degree are sufficient to reimburse the student for the opportunity cost of remaining in high school, the student will complete high school.

We now consider how various shocks to the local labor market will affect the decision to remain in school. First consider a shock that raises the wages for high school dropouts and high school graduates by the same amount. While this will have the effect of increasing the opportunity cost of a high school degree, it will not change the wage differential between graduates and dropouts. This might induce some students, particularly those with very high discount rates, to drop out of high school, but it should not have a particularly large effect on high school enrollments.

Now consider a transitory shock that increases demand for low-skilled workers. 
Such a shock will temporarily raise the wages of high school dropouts relative to high school graduates. This increases the opportunity cost of a high school degree, and may decrease the wage gap between graduates and dropouts for the first year or so of work. A temporary shock, however, will have a negligible effect on the return to a high school degree calculated over a student's entire working life. Again, enrollments should be relatively unaffected.

In order for a local labor market shock to have a substantial effect on high school enrollment, it must generate a long-term increase in the wages of dropouts relative to graduates. Such a shock will both increase the opportunity cost of a high school degree and reduce the return to a high school degree by narrowing the wage gap between dropouts and graduates for a substantial period of time.

A number of empirical studies have analyzed the effect of economic conditions on educational attainment and have thereby potentially tested the predictions from this simple theoretical model. Several studies have examined the effect of changes in the unemployment rate on high school dropout rates. To the extent that changes in unemployment rates tend to affect lowskilled workers more than high-skilled workers, it is possible to interpret a reduction in the unemployment rate as a flattening of the education-wage gradient.

Duncan (1965) conducted a very early study of the relationship between unemployment and dropout rates. She used the 1960 Census to calculate cohort-specific high school completion rates for men from 1902 to 1956. She found that a higher national unemployment rate at the time a cohort was of high school age increased the fraction of the cohort that remained in school. Rumberger (1983) used the first wave of the National Longitudinal Survey of Youth (NLSY79) to study the decision to drop out of high school.

He found that while a higher unemployment rate reduced the probability of dropping out among black and Hispanic men, it increased the probability of dropping out among white men. Both the Duncan and
Rumberger studies potentially suffer from omitted variable bias, Duncan's from unobserved national shocks and Rumberger's from unobserved local characteristics.

In contrast, Rees and Mocan (1997) analyzed panel data on district-level high school dropout rates for New York State from 1978 to 1987. Using a fixed-effects specification, they controlled for district-specific and yearspecific unobserved characteristics. They found that for a district with a dropout rate at the state average, a 1 percentage point increase in the county unemployment rate decreased the dropout rate by $2 \%$. One drawback of the fixed-effects approach used by Rees and Mocan is that it relies on shortterm variation in the within-district unemployment rate for identification. We expect such transitory changes in economic conditions to have relatively small effects on the dropout rate.

Findings of two studies are consistent with the prediction that long-term wage increases for low-skilled workers relative to high-skilled workers will reduce high school completion rates. Neumark and Wascher (1995) studied the effects of minimum wage increases using state-level panel data from 1977 to 1989 . They found that, controlling for state and year fixed effects, increases in the minimum wage decreased school enrollment among teenagers. Goldin and Katz (1997) found that states with a high fraction of employment in manufacturing had lower levels of high school completion in 1910 and smaller increases in high school completion between 1910 and 1928 than did other states. They argued that because most manufacturing jobs did not require a high school diploma, students in these states faced a lower return to a high school degree.

\section{The Coal Boom and Bust}

In this section, we describe the coal boom and bust of the 1970s and 1980s and the impact on the coal-mining areas of Kentucky and Pennsylvania. The Appalachian regions of these states have traditionally been relatively poor and also very dependent on the coal industry. The coal boom 
Figure 1. Coal Prices and Fraction of Earnings from Mining in Kentucky and Pennsylvania, 1969-1993.

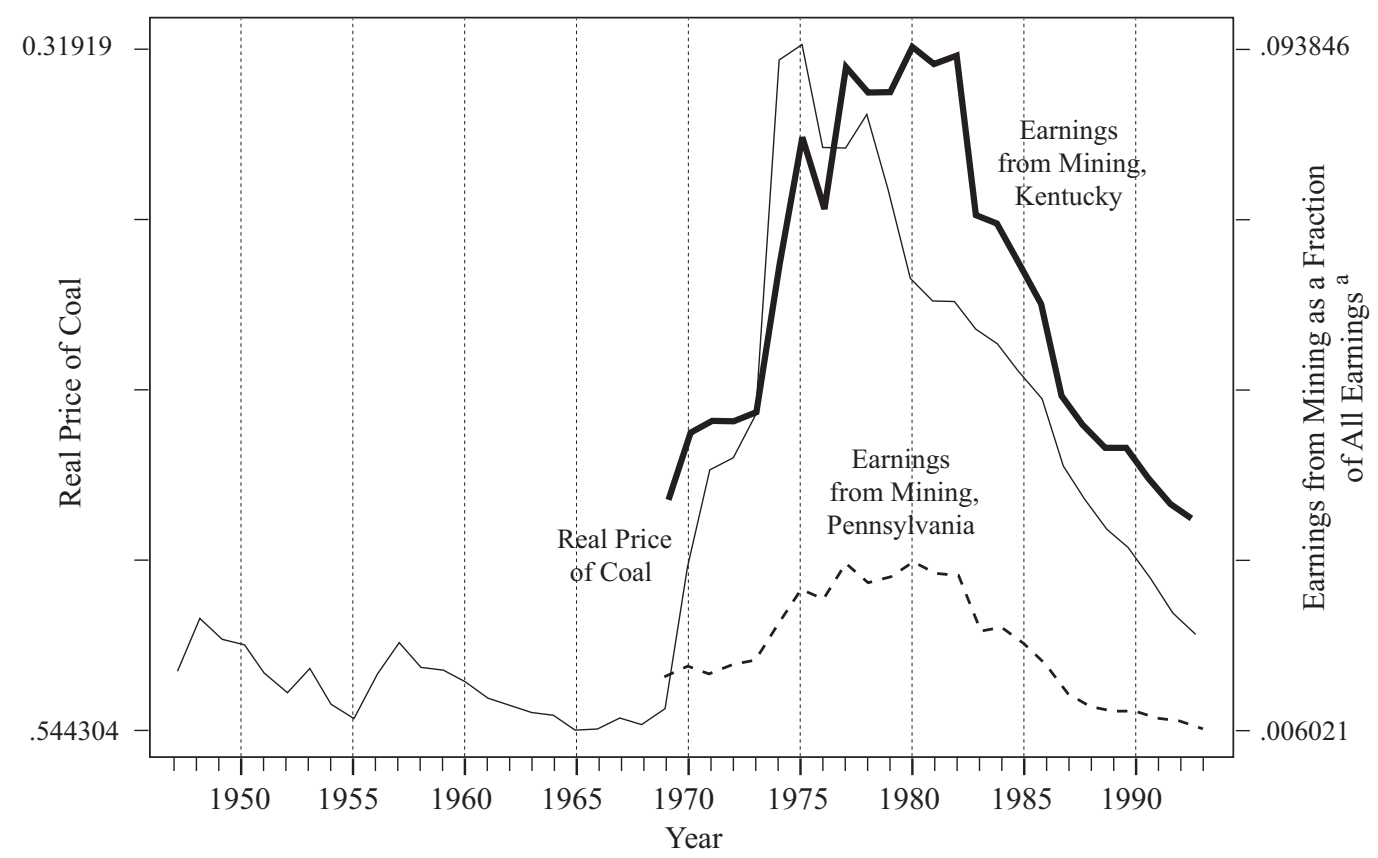

${ }^{\mathrm{a}}$ Minimum/maximum earnings from mining as a fraction of all earnings were $.02955 / .093846$ and $.006021 / .023269$ for Kentucky and Pennsylvania, respectively.

and bust also had large effects on coalproducing counties in Ohio and West Virginia, which we explore in related studies. ${ }^{1}$

In Figure 1, we plot the real price of coal over time, as well as the fraction of earnings in the two states attributed to mining. We can see that until 1969 the price of coal was relatively stable. Regulatory changes caused the coal price to increase $28 \%$ between 1969 and 1970, and the OPEC oil embargo caused the coal price to increase $44 \%$ between 1973 and 1974. These price increases generated a tremendous boom in the coal

\footnotetext{
${ }^{1}$ See Black, Daniel, and Sanders (2002) and Black, McKinnish, and Sanders (2003). We were unable to obtain adequate high school enrollment information on Ohio and West Virginia to include those states in the current study.
}

industry. In Kentucky, the fraction of earnings from mining more than tripled from about $3 \%$ to more than $9 \%$ between 1969 and 1977. In Pennsylvania, the fraction of earnings from mining doubled from roughly $1 \%$ to more than $2 \%$ between 1969 and 1977. In the graph, we can see that while the price of coal declined, coal earnings were stable for the period from 1978 and 1982. Starting around 1982, the coal industry busted. The bust occurred due to a drop in the price of coal, as well as the opening of alternative mines in the western United States and the automation of the mining process, which decreased demand for low-skilled coal miners.

These coal shocks were not felt equally in all counties in Kentucky and Pennsylvania. Some counties in these two states sit on major coal seams and benefited tremen- 
Figure 2. County per Capita Income Relative to the U.S. in Two Coal-Producing Counties, 1969 to 1993.

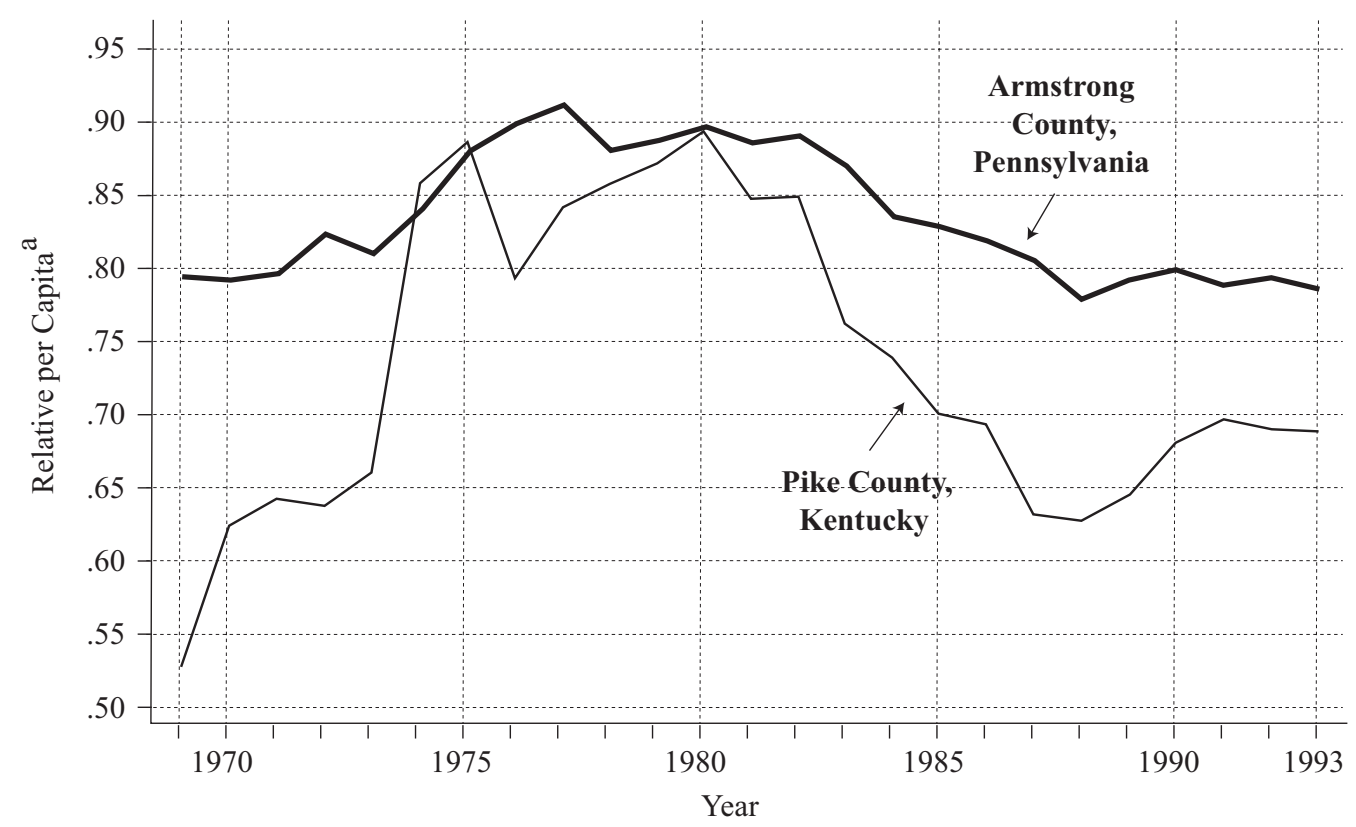

${ }^{\mathrm{a}}$ Minimum and maximum relative per capita income values for Pike County and Armstrong County, respectively, were $.52857 / .89604$ and $.77860 / .91301$.

dously from the coal boom. ${ }^{2}$ More than half of the counties in this region, however, have almost no coal reserves, and were largely unaffected by the coal boom and bust.

In Figure 2, we demonstrate the effect of the coal shocks on two coal-rich counties. We plot the ratio of county per capita personal income to per capita personal income in the United States between 1969 and 1993 for two very coal-rich counties, one in Kentucky and one in Pennsylvania. In 1969, Pike County, Kentucky, started

\footnotetext{
${ }^{2}$ There is one large seam in western Kentucky that is part of the Illinois coal basin, the very large Appalachian basin that runs through western Pennsylvania and eastern Kentucky, and one other seam in eastern Pennsylvania.
}

with per capita income that was only $56 \%$ of national per capita income. During the coal boom, this figure rose dramatically to $90 \%$ in 1980 , and then plummeted back down to $63 \%$ of national per capita income by 1988. A similar trend, though not as pronounced in magnitude, occurred in Armstrong County, Pennsylvania.

In Table 1, we compare the characteristics of coal-mining workers to the characteristics of all workers in our two states in 1970 and 1990. From the table, we see that coal employment was predominantly lowskilled. In $1970,45.2 \%$ of coal workers had less than eight years of education and a full $68.7 \%$ had less than a high school education. By comparison, in 1970, only $18.0 \%$ of all workers had less than eight years of education and $41.3 \%$ had less than a high school education. Even though education levels had increased overall by 1990, coal 
Table 1. Characteristics of Coal-Mining Workers in Kentucky and Pennsylvania: 1970 and 1990 Census Data.

\begin{tabular}{|c|c|c|c|c|}
\hline Years of Schooling & $\begin{array}{c}\text { Coal Workers, } \\
1970\end{array}$ & $\begin{array}{c}\text { All Workers } \\
1970\end{array}$ & $\begin{array}{c}\text { Coal Workers, } \\
1990\end{array}$ & $\begin{array}{c}\text { All Workers, } \\
1990\end{array}$ \\
\hline Less Than 8 Years & $45.2 \%$ & $18.0 \%$ & $10.7 \%$ & $4.3 \%$ \\
\hline 9 to 12 Years, No Diploma & 23.5 & 23.3 & 21.1 & 14.3 \\
\hline High School Graduate & 24.7 & 37.0 & 48.1 & 39.8 \\
\hline Some College & 4.6 & 10.5 & 14.5 & 23.4 \\
\hline College Graduate & 2.0 & 11.2 & 5.6 & 18.2 \\
\hline
\end{tabular}

Calculations made using the 1970 and1990 Public Use Micro Samples (PUMS) from the 1970 and 1990 Censuses.

workers in 1990 were still more likely to have low education than were workers in general.

Because the coal industry employed primarily low-skilled workers, the coal boom of the 1970s should have raised the earnings of high school dropouts relative to high school graduates. Likewise, the coal bust of the 1980s should have lowered earnings of high school dropouts relative to graduates. To confirm these effects, we use Census data from 1970, 1980, and 1990 to compare the changes in wages for high school dropouts and high school graduates between coal-mining areas and non-coalmining areas. ${ }^{3}$

Unfortunately, the Public Use Microdata Samples (PUMS) data do not identify county of residence in rural areas, only county groups with populations of at least 250,000 in 1970 and with populations of 100,000 in 1980 and 1990. Many of these county groups overlap areas that are both rich and poor in coal reserves. We divide the county groups in Kentucky and Pennsylvania into those with less than $0.5 \%$ of employment in coal

${ }^{3}$ Data from the Decennial Censuses are the only data suited to analyze wages by education level in coal-producing areas.

Because coal-producing areas are rural, sample sizes in most available micro-level panel data sets are extremely small. County-level economic data like those used below in the regression analysis do not contain wage information or information on earnings by education level. and those with more than $3 \%$ of employment in coal. ${ }^{4}$ County groups with between $0.5 \%$ and $3 \%$ of employment in coal are removed from the sample. Using 1970 and 1980 PUMS data on civilian male workers ages 25 to 40 with at least a 10th-grade education but no more than a high school degree, we estimate the regression

$$
\begin{aligned}
& \text { Wage }_{i}=\sum_{j=10}^{12} \beta_{1 j} d(j)_{i}+ \\
& \sum_{j=10}^{12} \beta_{2 j}\left[d(j)_{i} * \text { CoalArea }_{i}\right]+ \\
& \sum_{j=10}^{12} \beta_{3 j}\left[d(j)_{i} * d 80_{i}\right]+ \\
& \sum \beta_{4 j}\left[\stackrel{12}{d}(j)_{j=10} * d 80_{i} * \text { CoalArea }_{i}\right]+ \\
& X \beta_{5}+\varepsilon_{i},
\end{aligned}
$$

where Wage is the hourly wage, $d(j)$ is an indicator for completing $j$ years of educa-

\footnotetext{
${ }^{4}$ The final sample from all three Census years of civilian male workers ages 25-40 with at least a 10thgrade education but no more than a high school degree contains 5,849 workers in areas with at least $3 \%$ of employment in coal mining and 75,914 workers in areas with less than $0.5 \%$ employment in coal mining. 15,571 workers who lived in areas with $0.5-$ $3 \%$ of employment in coal mining are dropped from the sample. Unfortunately, because the county groups change over time, counties in the $<.5 \%$ employment group and counties in the $>3 \%$ employment group change from Census to Census. Furthermore, because 1970 county groups cross state lines, the sample includes workers in 1970 from outside of Kentucky and Pennsylvania.
} 
Table 2. Changes in the Education-Wage Gradient in County Groups with at Least 3\% Employment in Mining Relative to Areas with Less Than 0.5\% Employment in Mining. (1970, 1980, and 1990 Census Data; Standard Errors in Parentheses)

\begin{tabular}{lcc}
\hline Educational Level & Wage Change & Wage Change \\
from 1970 to 1980 & from 1980 to 1990 \\
\hline Workers with a 10th Grade Education & 3.852 & -2.952 \\
Workers with an 11th Grade Education & $(1.343)$ & $(0.653)$ \\
Workers with a High School Degree & 1.764 & -1.658 \\
& $(1.642)$ & $(0.623)$ \\
$\mathrm{N}$ & 1.078 & -1.100 \\
\end{tabular}

Notes: Wages for civilian men 25-40 years old with at least a 10th grade education but no more than a high school degree are calculated from the 1970, 1980, and 1990 PUMS. Workers in county groups in which at least $3 \%$ of employment was in coal mining are compared to those in which there was no more than $0.5 \%$ employment in coal mining. Regressions also control for age and race (black, white).

tion, $d 80$ is an indicator for 1980, CoalArea is an indicator for residence in a county group with at least $3 \%$ of employment in coal mining, and $X$ contains worker age and race indicators (white, black). ${ }^{5}$ The coefficient $\beta_{4 j}$ is therefore a differences-indifferences estimate of the effect of the coal boom on the wages of civilian male workers ages 25-40 with $j$ years of education. Specifically, $\beta_{4 j}$ gives the change in wage of workers with $j$ years of education between 1970 and 1980 in coal-mining areas relative to areas without coal mining.

The results from equation (4) are reported in the first column of Table 2. Consistent with a boom in the coal industry, the wages increased in coal-mining areas relative to areas without coal mining between 1970 and 1980 for all three education groups, but the increase was greater for high school dropouts than for high school graduates. Relative wages increased by $\$ 3.85$

\footnotetext{
${ }^{5}$ The wage measure is total wage and salary earnings divided by hours of work, obtained by multiplying weeks worked last year by average number of hours worked per week. The 1970 PUMS only reports hours per week and weeks of work as intervals. We use the median value of each interval, obtained using the 1980 PUMS. Wage observations below 0.20 and above 100 are removed from the sample.
}

for workers with just a 10th-grade education, by $\$ 1.76$ for workers with just an 11 thgrade education, and by $\$ 1.08$ for workers with a high school degree. Therefore, we see evidence that the coal boom reduced the wage differential between high school dropouts and high school graduates, flattening out the education-wage gradient.

The analogous regression is estimated for the bust period from 1980 to 1990 and reported in column (2) of Table 2. Consistent with a bust in the coal industry, the wages decreased in coal-mining areas relative to areas without coal mining between 1980 and 1990 for all three education groups, but the wages decreased more for high school dropouts than for high school graduates. Wages decreased by $\$ 2.95$ for workers with just a 10th-grade education, by $\$ 1.66$ for workers with just an 11 th-grade education, and by $\$ 1.10$ for workers with a high school degree. The bust almost perfectly erased the wage gains obtained during the boom. In doing so, it widened the wage differential between high school dropouts and graduates, increasing the education-wage gradient.

The coal boom and bust were relatively long-term shocks, reducing or increasing the wage differential between dropouts and graduates for many years. Furthermore, residents of coal-mining areas during the 
boom would likely have perceived that the coal boom was a long-term shock, because they would have observed the enormous levels of capital investment being made to expand existing mines and open many new ones. $^{6}$ As the coal boom and bust were long-term exogenous shocks to the return to a high school degree, they are well suited for testing the basic predictions of the human capital model.

\section{Graphical Analysis of High School Enrollment}

We expect to see high school enrollment rates in counties with coal mining to decrease during the boom years in the 1970s, and to increase during the bust years of the 1980 s, relative to high school enrollment rates in counties without coal mining. Because coal miners are almost exclusively male, we would expect these trends to be much more apparent for male students than for female students. Unfortunately, gender-specific data on high school enrollment or graduation at the county level are not available for our states and time period of interest, so we are unable to perform gender-specific analysis.

We use state administrative data on annual public school enrollment by grade level for all counties in Kentucky and Pennsylvania from 1971 to 1990 . We cannot calculate enrollment rates by individual grade level because we do not have annual

\footnotetext{
${ }^{6}$ The capital investors also perceived that the shift in demand for coal was long-term. This perception was based on the shift to coal-based electricity production. Electricity can be produced from several fuels, but because of interfuel substitution costs, "it would take a major, enduring change in relative fuel prices to alter [fuel choice]" (Harvey 1986). Between 1973 and 1982, coal largely replaced gas and oil as a source of electricity production. As a result, the demand for coal itself has remained high, while alternative mines in the West and automated mining technology have reduced the demand for Appalachian coal workers. These factors that reduced the demand for Appalachian coal miners would have been largely unanticipated by miners during the boom, so they likely perceived the boom to be more permanent than it was.
}

county-level population counts by age but only by 5 -year age group. We therefore calculate the high school enrollment rate as the total enrollment in grades 9 to 12 divided by the population age 15 to 19 , and the grade school enrollment rate as the total enrollment in grades 5 to 8 divided by the population age 10 to 14 . We would prefer to use ages 15 to 18 in the denominator of our high school enrollment rate and ages 11 to 14 in the denominator of our grade school enrollment rate, but annual county-level population numbers are only available for these 5-year age groups. In general, this should not affect our analysis unless the coal boom induced migration of 19-year-old men who had already completed high school in other states or counties. We address this point later in the paper.

Our strategy is to compare changes in high school enrollment rates over time in counties with large coal deposits to the rates in counties without coal. ${ }^{7}$ To this end, we divide counties into three groups. We label counties with at least one billion tons of coal reserves "Big Coal" counties; those with between 100 million and one billion tons, "Medium Coal" counties; and those with less than 100 million tons, "Low Coal" counties. These cutoffs are somewhat arbitrary, but we generally observe considerable mining activity in counties with at least one billion tons and almost no mining activity in counties with less than 100 million tons. ${ }^{8}$ We calculate annual aggregate high school and grade school enrollment rates for each of these three categories.

${ }^{7}$ Information on county coal reserves was obtained from geological surveys conducted by each state. We obtained coal reserve information for Kentucky from the Kentucky Geological Survey's Kentucky Coal Resources Information Database. For Pennsylvania, we used estimates from Edmunds (1972). See Black, Daniel, and Sanders (2002) for additional information.

${ }^{8}$ We could divide counties into groups based on their actual employment in mining, as we did in our wage analysis above. But this measure is less exogenous. Unobserved characteristics of the counties might have caused some to develop larger coal-mining industries over time. County-level measures of coal reserves are preferable. 
Figure 3. Kentucky High School Enrollment, 1971-1990.

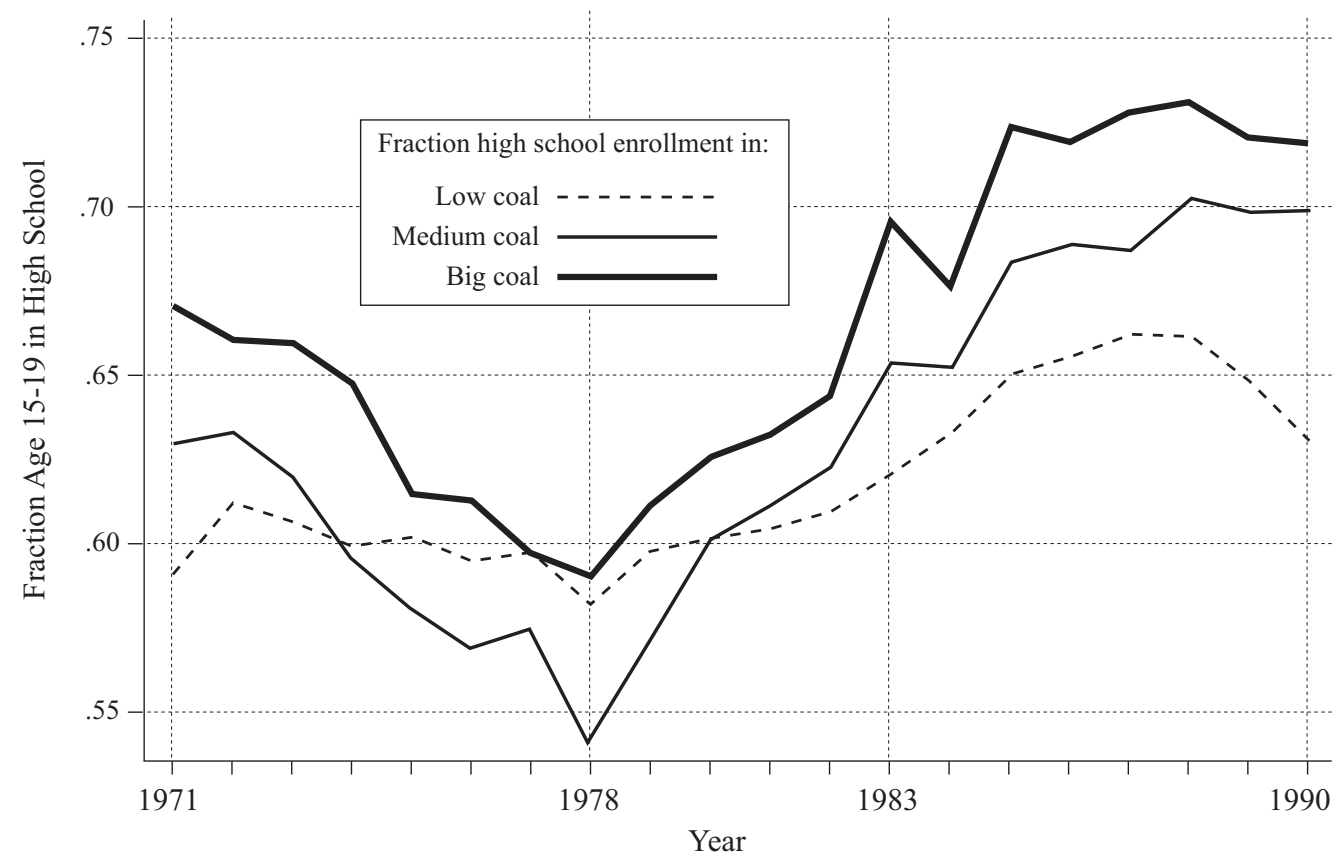

Note: We highlight four years: 1971, the initial year of our data; 1978 , the last year of the coal boom; 1983, the first year of the coal bust; and 1990, the final year of our data.

In Figure 3, we plot high school enrollment trends for Kentucky. Because coalmining areas in Kentucky are largely rural, we only use counties that do not belong to a metropolitan statistical area, to avoid comparing rural coal-rich counties to urban non-coal counties. There are 17 Big Coal counties, 14 Medium Coal counties, and 71 Low Coal counties in the Kentucky sample. Figure 3 plots high school enrollment rates for the Big Coal, Medium Coal, and Low Coal categories.

We see that, as predicted, the Big Coal high school enrollment rate was decreasing relative to enrollment rates in Low Coal counties during the boom period from 1971 to 1978 . Figure 1 shows that the coal boom leveled off around 1978. After 1978, high school enrollment in Big Coal areas was increasing relative to enrollment in Low Coal areas. The pattern for Medium Coal counties closely tracks that for High Coal counties: again, the high school enrollment rate decreased relative to the Low Coal rate until 1978, after which the Medium Coal rate increased relative to the Low Coal rate.

It is possible that the coal boom increased the fraction of families in counties with coal reserves that were able to send their children to private school. This would generate a pattern in public high school enrollment rates similar to what we observe in Figure 3. If private school attendance explains the patterns observed in Figure 3, then we expect to see similar patterns in public grade school enrollment. In Figure 4 , we repeat the analysis performed in Figure 3, but for public school enrollment rates for grades 5 to 8 . In stark contrast to Figure 3, we see that grade school enrollment rates are almost indistinguishable 
Figure 4. Kentucky G5-G8 Enrollment, 1971-1990.

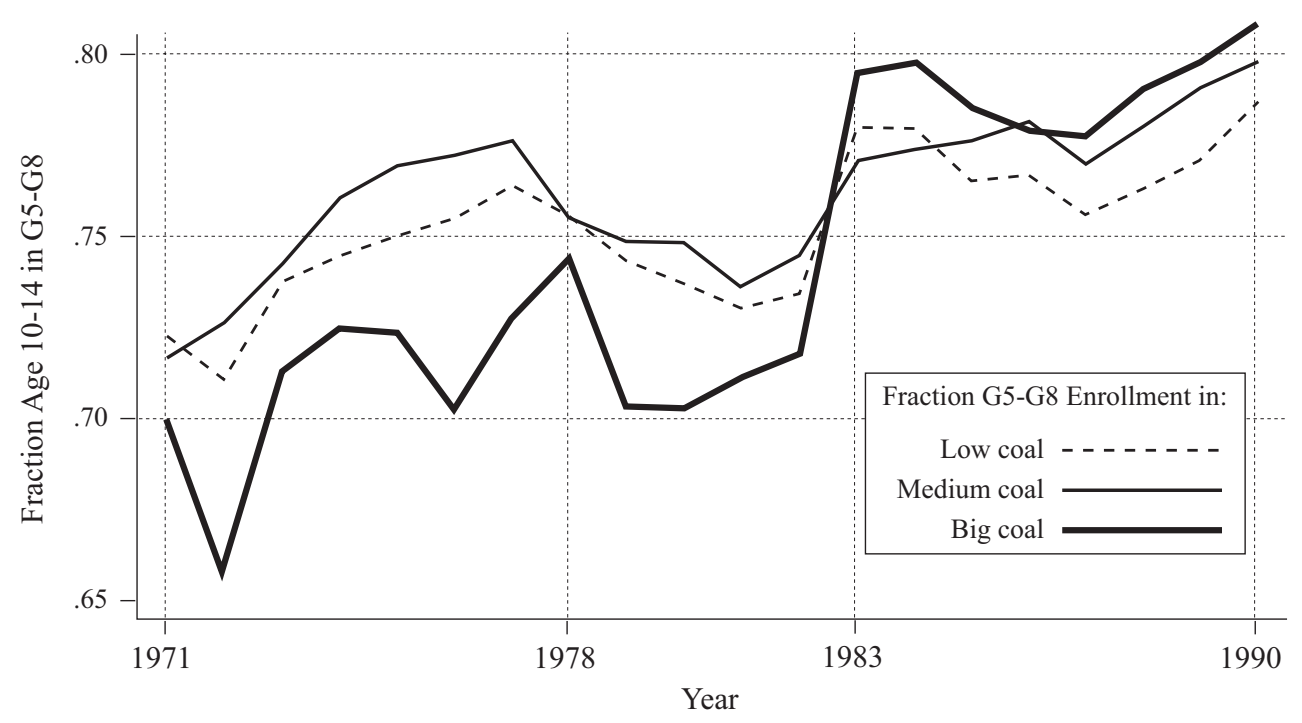

between the Big Coal, Medium Coal, and Low Coal counties. ${ }^{9}$

\section{Instrumental Variables Analysis of High School Enrollment}

Ideally, we would like to estimate the relationship between changes in the wages of high school dropouts and changes in high school enrollment, controlling for wages of high school graduates. Unfortunately, the necessary wage data are not available at the county level. We use the Regional Economic Information System (REIS) data provided by the Bureau of Economic Analysis. These data report annual county-level earnings and employment. We divide total real county earnings by county employment to obtain a measure of earnings per worker.

\footnotetext{
${ }^{9} \mathrm{~A}$ similar, although more modest, difference in trends between high school and grade school enrollment in coal-rich counties compared to counties without coal can be observed in data from Pennsylvania. These graphs are available upon request from the authors.
}

We begin with a baseline regression model of the form

$$
\begin{gathered}
\text { FrHS }_{c s t}=\beta_{0}+\beta_{1} \text { EarnPW }_{c s t}+ \\
\beta_{2} \text { FrGS }_{c s t}+\left(\text { State }_{s} * \text { Year }_{t}\right) \beta_{3}+\varepsilon_{c s t},
\end{gathered}
$$

where $\mathrm{FrHS}_{\text {cst }}$ is the logarithm of the fraction of residents age 15 to 19 enrolled in high school in county $c$ in state $s$ and year $t$. EarnPW is the logarithm of earnings per worker. $\operatorname{FrGS}$ is the logarithm of the fraction of residents age 10 to 14 enrolled in grades 5 to 8 . States is a vector of state indicators and $\mathrm{Year}_{t}$ is a vector of year indicators. Because we are controlling for stateyear effects, the estimation design purges the data of anything that varies over time at the state level.

Estimating equation (5) will likely produce biased results, because counties will differ in unobserved ways that affect both their economic well-being and their tastes for education. For this reason, we estimate equation (5) in differences instead of in levels:

$$
\begin{gathered}
\Delta \text { FrHS }_{\text {ist }}=\beta_{0}+\beta_{1} \Delta \operatorname{EarnP} W+ \\
\beta_{2} \Delta \operatorname{FrGS}+\left(\text { State }_{s} * \text { Year }_{t}\right) \beta_{3}+\Delta \varepsilon_{\text {ist }},
\end{gathered}
$$


where $\Delta X_{t}=X_{t}-X_{t-1}$. Of course, in equation (6), changes in earnings per worker do not necessarily reflect long-term changes in the earnings of high school dropouts relative to high school graduates. We therefore make explicit use of the variation from the shocks to the coal industry, which we know does generate long-term changes in the wage differential between dropouts and graduates. We use an instrumental variables (IV) model to capture the changes in county earnings per worker that can be attributed to the coal shocks. Our firststage regression model is

$$
\begin{gathered}
\Delta \text { EarnPW }_{i s t}=\alpha_{0}+\alpha_{1} \Delta(\text { CoalValue })_{i s t}+ \\
\alpha_{2} \Delta \text { FrGS }_{\text {ist }}+\left(\text { State }_{s} * \text { Year }_{t}\right) \alpha_{3}+\mu_{i s t}{ }^{\circ}
\end{gathered}
$$

Our instrument is the value of coal reserves in the county. The larger the coal reserves in the county, the more mineable the county's coal and the more the county will profit from the coal boom. We use two different specifications of our instrument. The first is the logarithm of the amount of coal reserves multiplied by the change in the logarithm of the real price of coal. It is evident from Figure 1 that the changes in earnings lag slightly behind the changes in the price of coal, because it can take some time to open a new mine. Therefore, we include a lag of the value of coal reserves as well.

For our second specification of the instrument, we use three indicators for whether the county is a Big Coal, Medium Coal, or Low Coal county. We then use three time-period indicators: one for the boom from 1970 to 1977 , another for the stable period at the peak from 1978 to 1982, and the last for the bust from 1983 to 1990. Our instruments are the interactions of these two sets of dummy variables. The second-stage regression then takes the form

$$
\begin{gathered}
\Delta F r H S_{i s t}=\gamma_{0}+\gamma_{1} \Delta{\operatorname{Ear} \hat{n} P W_{i s t}}+ \\
\gamma_{2} \Delta F r G S_{i s t}+\left(\text { State }_{s} * \text { Year }_{t}\right) \gamma_{3}+\varepsilon_{i s t}^{\prime} .
\end{gathered}
$$

The predicted value of the change in EarnPW used in equation (8) reflects changes in earnings per worker that can be attributed to the coal boom and bust, therefore reflecting changes in worker wages associated with a long-term increase in returns for low-skilled workers relative to returns for high-skilled workers. In contrast, much of the time-series variation in earnings per worker captured in the differences regression in equation (6) will reflect relatively short-term fluctuations in earnings opportunities. This short-term variation will have only a modest impact on the total earnings stream of high school dropouts, and therefore will have a relatively small effect on the decision to leave high school. As a result, we expect our estimate of $\gamma_{1}$ to be larger in magnitude than $\beta_{1}$.

We report our results in Table 3 . The first row reports the coefficient on earnings per worker obtained by estimating the firstdifferences regression in equation (6) by OLS. The other two rows report the estimates obtained using IV estimation with our two different instruments. The first column reports the results for the entire sample. The OLS coefficient is small, positive, and statistically insignificant. The OLS results indicate that there is no relationship between earnings per worker and high school enrollment rates. This is consistent with our expectation that short-term fluctuations in economic conditions have a relatively small effect on school enrollment decisions. ${ }^{10}$

In the second row, we report the IV estimates we obtain using the coal price instrument. The coefficient estimate is negative, large in magnitude, and highly statistically significant. The coefficient of -0.648 implies that a $10 \%$ increase in earnings per worker associated with the coal boom reduced high school enrollment by $6.5 \%$. This is a very large effect, but it must be remembered that this is a $10 \%$ increase in earnings per worker associated with the coal shocks. In other words, this $10 \%$ increase in earnings per worker most likely reflects an even larger increase in earnings per working high school dropout. The

\footnotetext{
${ }^{10}$ Similar results of small magnitude are obtained if we restrict the sample to counties with low coal reserves.
} 
Table 3. Effect of Earnings per Worker on the

Fraction Age 15 to 19 Enrolled in High School, 1972-1990.

(Huber-White Robust Standard Errors in Parentheses; First-Stage Partial F-Statistics in Brackets)

\begin{tabular}{|c|c|c|c|c|}
\hline Regression Model & $\begin{array}{l}\text { Kentucky and } \\
\text { Pennsylvania }\end{array}$ & Kentucky Only & $\begin{array}{c}\text { Pennsylvania } \\
\text { Only }\end{array}$ & $\begin{array}{l}\text { Pennsylvania } \\
\text { with } \\
\text { MSA Counties }\end{array}$ \\
\hline First-Differences & $\begin{array}{c}0.003 \\
(0.033)\end{array}$ & $\begin{array}{c}0.003 \\
(0.034)\end{array}$ & $\begin{array}{c}0.024 \\
(0.039)\end{array}$ & $\begin{array}{c}0.009 \\
(0.028)\end{array}$ \\
\hline IV Coal Price Instrument & $\begin{array}{l}-0.648 * * * \\
(0.179) \\
{[22.4]}\end{array}$ & $\begin{array}{l}-0.715 \text { **** } \\
(0.209) \\
{[19.4]}\end{array}$ & $\begin{array}{c}-0.229 \\
(0.230) \\
{[12.0]}\end{array}$ & $\begin{array}{c}-0.384 * * \\
(0.192) \\
{[16.3]}\end{array}$ \\
\hline IV Coal Seam Instrument & $\begin{array}{l}-0.490 * * * \\
(0.104) \\
{[13.3]}\end{array}$ & $\begin{array}{l}-0.544 * * * \\
(0.120) \\
{[12.4]}\end{array}$ & $\begin{array}{c}-0.205 \\
(0.153) \\
{[13.0]}\end{array}$ & $\begin{array}{l}-0.220 * * \\
(0.097) \\
{[7.7]}\end{array}$ \\
\hline $\mathrm{N}$ & 2,622 & 1,938 & 684 & 1,273 \\
\hline
\end{tabular}

Notes: The sample consists of all non-MSA counties in Kentucky and Pennsylvania. The dependent variable is the change in the logarithm of the fraction of children ages 15 to 19 enrolled in grades 9 to 12 . The table reports the coefficient on the change in the logarithm of earnings per worker. Regressions include controls for the logarithm of the fraction of children ages 10 to 14 enrolled in grades 5 to 8 and state-year effects (and an MSA dummy in column 4). The Coal Price instrument is the logarithm of the size of coal reserves multiplied by the change in the logarithm of the real price of coal and its one-year lag. The Coal Seam instrument consists of indicators for size of coal reserves (less than 100 million tons, 100 million to 1 billion tons, more than 1 billion tons) interacted with time period indicators (boom: 1972-77; peak: 1978-82; bust: 1983-90).

**Statistically significant at the .05 level; ***at the .01 level.

partial F-statistic from the first stage is reported in brackets. The F-statistic of 22 indicates that the change in value of coal reserves is a strong instrument for earnings per worker. In the final row, we use the interaction of coal reserve size and time period indicators as the instrument. The coefficient estimate of -0.490 is somewhat smaller than what was obtained with the first instrument, but still large and statistically significant.

In the second column, we report the results obtained using only the counties in Kentucky. These results are very similar to those obtained for the full sample, suggesting an elasticity in the range of -0.54 to -0.72 . The similarity in the results is not surprising, because Kentucky has many more counties than Pennsylvania, particularly once the MSA counties are removed from the sample. Additionally, Kentucky has more "big coal" counties than Pennsylvania. Therefore, the results for Kentucky and the results for Pennsylvania and Kentucky combined should be similar.
In the third column, we report results using only the counties in Pennsylvania. The IV results for Pennsylvania, while negative, are smaller and statistically insignificant. It is important to remove the MSA counties from the sample for Kentucky because the coal-producing areas of Kentucky are overwhelmingly rural. The coal-producing areas of Pennsylvania, however, are both rural and metropolitan, so it is reasonable to estimate the model including the MSA counties (with an MSA indicator in the model). The results of including the MSA counties in the estimation for Pennsylvania are reported in the column (4). The results are statistically significant and indicate an elasticity in the range of -0.22 to -0.38 .

While these results indicate a strong negative relationship between earnings per worker and high school enrollment, one remaining issue must be addressed. The coal boom generated migration of workers into coal-producing areas. Because we divide high school enrollment 
Table 4. Effect of Earnings per Worker on Total High School Enrollment, 1972-1990. (Huber-White Robust Standard Errors in Parentheses; First-Stage Partial F-Statistics in Brackets)

\begin{tabular}{|c|c|c|c|c|}
\hline Regression Model & $\begin{array}{l}\text { Kentucky and } \\
\text { Pennsylvania }\end{array}$ & Kentucky Only & $\begin{array}{c}\text { Pennsylvania } \\
\text { Only }\end{array}$ & $\begin{array}{c}\text { Pennsylvania } \\
\text { with } \\
\text { MSA Counties }\end{array}$ \\
\hline First-Differences & $\begin{array}{c}0.010 \\
(0.033)\end{array}$ & $\begin{array}{c}0.010 \\
(0.034)\end{array}$ & $\begin{array}{c}0.030 \\
(0.037)\end{array}$ & $\begin{array}{c}0.019 \\
(0.026)\end{array}$ \\
\hline IV Coal Price Instrument & $\begin{array}{l}-0.555 * * * \\
(0.159) \\
{[22.0]}\end{array}$ & $\begin{array}{l}-0.587 * * * \\
(0.189) \\
{[18.9]}\end{array}$ & $\begin{array}{l}-0.219 \\
(0.205) \\
{[12.1]}\end{array}$ & $\begin{array}{c}-0.293 * * \\
(0.148) \\
{[16.2]}\end{array}$ \\
\hline IV Coal Seam Instrument & $\begin{array}{l}-0.441 * * * \\
(0.098) \\
{[13.6]}\end{array}$ & $\begin{array}{l}-0.499 * * * \\
(0.116) \\
{[12.7]}\end{array}$ & $\begin{array}{c}-0.116 \\
(0.119) \\
{[13.2]}\end{array}$ & $\begin{array}{l}-0.153 \\
(0.081) \\
{[7.7]}\end{array}$ \\
\hline $\mathrm{N}$ & 2,622 & 1,938 & 684 & 1,273 \\
\hline
\end{tabular}

Notes: The sample consists of all non-MSA counties in Kentucky and Pennsylvania. The dependent variable is the change in the logarithm of the number of students enrolled in grades 9 to 12 . The table reports the coefficient on the change in the logarithm of earnings per worker. Regressions include controls for the logarithm of the fraction of children ages 10 to 14 enrolled in grades 5 to 8 , the logarithm of the population ages 15 to 19, and state-year effects (and an MSA dummy in column 4). The Coal Price instrument is the logarithm of the size of coal reserves multiplied by the change in the logarithm of the real price of coal and its one-year lag. The Coal Seam instrument consists of indicators for size of coal reserves (less than 100 million tons, 100 million to 1 billion tons, more than 1 billion tons) interacted with time period indicators (boom: 1972-77; peak: 1978-82; bust: 1983-90).

$* *$ Statistically significant at the .05 level; ***at the .01 level.

by the population age 15 to 19 , the inmigration of 19-year-olds who had already completed high school would also cause a decrease in high school enrollment rates in coal-producing counties during the coal boom. The concern is that the change in the dependent variable, the high school enrollment rate, might be driven by an increase in the denominator due to economic migration. Therefore, in Table 4, we re-estimate our models using the level of high school enrollment rather than the enrollment rate, moving the measure of high school age population to the right-hand side of the regression,

$$
\begin{gathered}
\Delta H S_{i s t}=\beta_{0}+\beta_{1} \Delta E \text { EarnPW }+\beta_{2} \Delta F r G S+ \\
\beta_{3} H S P o p+\left(\text { State }_{s} * \text { Year }_{t}\right) \beta_{4}+\Delta \varepsilon_{i s t},
\end{gathered}
$$

where $H S$ is the logarithm of total enrollment in grades 9 to 12 and HSPop is the logarithm of population age 15 to 19 .

If our results in Table 3 are largely the result of changes in the population age
15 to 19 , we expect to see a substantial change in our estimates when we move the population measure to the right-hand side of the regression. The coefficients in Table 4 are somewhat smaller in magnitude than those in Table 3 , but overall the differences are modest. The results still suggest large effects of the coal shocks on high school enrollment. While the evidence is somewhat circumstantial because we cannot directly observe the characteristics of the coal migrants, it does not appear that our results are an artifact of economic migration. ${ }^{11}$

\footnotetext{
${ }^{11}$ Additionally, Black, McKinnish, and Sanders (2005) use the 1970,1980 , and 1990 PUMS to compare population growth for men and women between coal-mining county groups and county groups without coal mining following a procedure similar to the wage analysis performed in this paper. This analysis suggests that in-migration during the coal boom was much more prevalent among men in their 30s than among men of high school age.
} 
Copyright of Industrial \& Labor Relations Review is the property of Cornell University. The copyright in an individual article may be maintained by the author in certain cases. Content may not be copied or emailed to multiple sites or posted to a listserv without the copyright holder's express written permission. However, users may print, download, or email articles for individual use. 